\title{
Seis sombreros para pensar en la biblioteca
}

Patricia Mariel Sanoner ${ }^{(1)}$

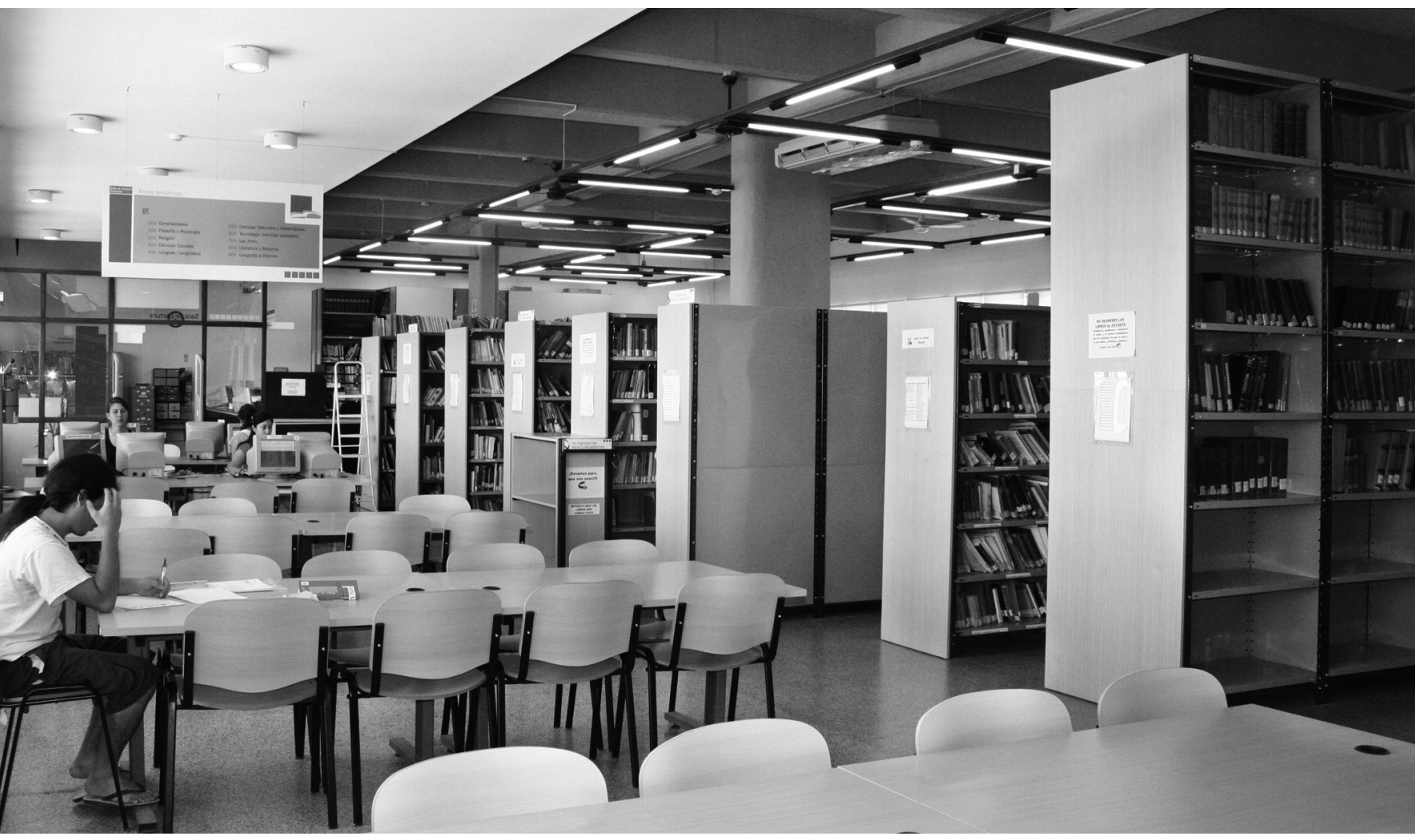

(1) Bibliotecaria de la FADU,

FHUC e ISM. 
Utilizando la Guía de pensamiento que nos propone Edward De Bono (2006) a través de la cual predica el uso de distintos sombreros para pensar de determinada manera es que voy a tratar de escribir (y describir) en pocas palabras lo que ha sucedido en la Biblioteca durante los 17 años que llevo trabajando en ella.

\begin{tabular}{|c|c|c|c|c|}
\hline $\begin{array}{l}\text { Sombrero Blanco } \\
\text { pensamiento } \\
\text { neutro }\end{array}$ & $\begin{array}{l}\text { Sombrero Rojo } \\
\text { pensamiento } \\
\text { emocional }\end{array}$ & $\begin{array}{l}\text { Sombrero Negro } \\
\text { pensamiento } \\
\text { negativo }\end{array}$ & $\begin{array}{l}\text { Sombrero Amarillo } \\
\text { pensamiento } \\
\text { positivo }\end{array}$ & $\begin{array}{l}\text { Sombrero Verde } \\
\text { pensamiento } \\
\text { creativo }\end{array}$ \\
\hline $\begin{array}{l}\text { Ingresé a trabajar } \\
\text { en la biblioteca en } \\
\text { el año 1990.El Pro- } \\
\text { fesor Mauricio Epel- } \\
\text { baum era el Decano } \\
\text { de la Facultad y el } \\
\text { Sr. Elbio Díaz era el } \\
\text { Secretario adminis- } \\
\text { trativo de la misma. }\end{array}$ & $\begin{array}{l}\text { No sabía de qué se } \\
\text { trataba todo esto. } \\
\text { No tengo que llorar, } \\
\text { no tengo que Ilorar, } \\
\text { no tengo que Ilorar, } \\
\text { no tengo que... } \\
\text { buaaa!!!Mauricio } \\
\text { me dijo que iba a } \\
\text { ir a trabajar en la } \\
\text { biblioteca. Yo casi } \\
\text { me desmayo pero } \\
\text { ante él demostré } \\
\text { seguridad y "cono- } \\
\text { cimiento". Él dijo } \\
\text { que confiaba en } \\
\text { mí y que seguro no } \\
\text { lo defraudaría. Yo } \\
\text { pensé que si me } \\
\text { iba y no volvía más } \\
\text { quizá nadie se daría } \\
\text { cuenta pero, había } \\
\text { un problema: mi } \\
\text { papá también traba- } \\
\text { jaba en la Facultad } \\
\text { y me podrían "ras- } \\
\text { trear" a través de él. }\end{array}$ & $\begin{array}{l}\text { No voy a poder } \\
\text { trabajar acá. La } \\
\text { directora de la } \\
\text { biblioteca no me } \\
\text { quiere, me voy a } \\
\text { tener que ir. Seguro } \\
\text { que logra que me } \\
\text { despidan. Nunca } \\
\text { supe organizar } \\
\text { nada, ni siquiera } \\
\text { mi guardarropa, } \\
\text { como voy a poder } \\
\text { organizar una } \\
\text { biblioteca. Para } \\
\text { colmo de males } \\
\text { hay cada vez más } \\
\text { libros. ¿Qué va a } \\
\text { pasar conmigo? } \\
\text { ¿Qué voy a hacer? }\end{array}$ & $\begin{array}{l}\text { Seguro que puedo, } \\
\text { que me voy a } \\
\text { adaptar Es un tra- } \\
\text { bajo que me gusta } \\
\text { y tengo la capaci- } \\
\text { dad para realizarlo. } \\
\text { La única manera } \\
\text { de "lidiar" con esto } \\
\text { es "tomando al toro } \\
\text { por las astas", es } \\
\text { decir, estudiando y } \\
\text { capacitándome. }\end{array}$ & $\begin{array}{l}\text { Si sigo estudiando, } \\
\text { aunque esta vez sea } \\
\text { a distancia, enton- } \\
\text { ces voy a poder } \\
\text { superarme. Pero } \\
\text { nunca debo olvi- } \\
\text { darme de mis oríge- } \\
\text { nes y siempre debo } \\
\text { seguir tratando de } \\
\text { ser mejor persona. } \\
\text { La creatividad está } \\
\text { en cómo lograr } \\
\text { esto sin "caer" en } \\
\text { la tentación. Tengo } \\
\text { que seguir capaci- } \\
\text { tándome para así } \\
\text { poder brindar un } \\
\text { mejor servicio a } \\
\text { nuestros usuarios. } \\
\text { No tenemos mucho } \\
\text { pero tenemos } \\
\text { creatividad para } \\
\text { solucionar todos los } \\
\text { problemas que se } \\
\text { nos puedan pre- } \\
\text { sentar. }\end{array}$ \\
\hline
\end{tabular}




\begin{tabular}{|c|c|c|c|c|}
\hline $\begin{array}{l}\text { Sombrero Blanco } \\
\text { pensamiento } \\
\text { neutro }\end{array}$ & $\begin{array}{l}\text { Sombrero Rojo } \\
\text { pensamiento } \\
\text { emocional }\end{array}$ & $\begin{array}{l}\text { Sombrero Negro } \\
\text { pensamiento } \\
\text { negativo }\end{array}$ & $\begin{array}{l}\text { Sombrero Amarillo } \\
\text { pensamiento } \\
\text { positivo }\end{array}$ & $\begin{array}{l}\text { Sombrero Verde } \\
\text { pensamiento } \\
\text { creativo }\end{array}$ \\
\hline $\begin{array}{l}\text { La colección estaba } \\
\text { conformada por } \\
\text { libros, revistas y } \\
\text { mapas con un total } \\
\text { de } 10.000 \text { volúme- } \\
\text { nes aproximada- } \\
\text { mente. La biblioteca } \\
\text { funcionaba en el } \\
\text { entrepiso del edifi- } \\
\text { cio que ocupaba la } \\
\text { Facultad en calle } 9 \\
\text { de julio } 2655 \text {. }\end{array}$ & $\begin{array}{l}\text { Los libros se me } \\
\text { vienen encima. Me } \\
\text { persiguen. Yo no } \\
\text { encuentro nada, } \\
\text { esto es un desastre. } \\
\text { Vivo con libros, } \\
\text { sueño con libros. } \\
\text { Que suerte que } \\
\text { están Alcira (Plez) } \\
\text { y Carlos (Ríos) para } \\
\text { bancarme...qué } \\
\text { compañeros de } \\
\text { lujo.La biblio- } \\
\text { teca en cualquier } \\
\text { momento se iba } \\
\text { a caer encima del } \\
\text { Sr. Díaz (Secre- } \\
\text { tario de la Facul- } \\
\text { tad cuya oficina } \\
\text { estaba debajo de } \\
\text { la Biblioteca), para } \\
\text { colmo de males } \\
\text { era GRANDOTE } \\
\text { y seguro que con } \\
\text { "una mano" lograba } \\
\text { esconderme debajo } \\
\text { de un escritorio }\end{array}$ & $\begin{array}{l}\text { Alcira ya se jubila y } \\
\text { ¿si El Carli también } \\
\text { se va? Seguro que } \\
\text { me quedo sola } \\
\text { con todos estos } \\
\text { libros... ¿Qué voy a } \\
\text { hacer? Las paredes } \\
\text { se quiebran por } \\
\text { el sobrepeso del } \\
\text { entrepiso (no de los } \\
\text { bibliotecarios). Nos } \\
\text { vamos a caer, YA } \\
\text { NO HAY DUDAS } \\
\text { AL RESPECTO. }\end{array}$ & $\begin{array}{l}\text { El Carli es de HIE- } \\
\text { RRO, ya todos nos } \\
\text { dicen LOS CHICOS } \\
\text { DE LA BIBLIO- } \\
\text { TECA. Somos los } \\
\text { dos mosqueteros } \\
\text { y juntos podemos } \\
\text { enfrentarnos a } \\
\text { todo y a todos. } \\
\text { En el año } 1993 \\
\text { se decide que la } \\
\text { biblioteca se mude } \\
\text { a } 9 \text { de Julio } 2765 . \\
\text { Qué suerte, menos } \\
\text { mal, zafamos del } \\
\text { Sr. Díaz. Cada vez } \\
\text { hay más alumnos } \\
\text { ya que se comen- } \\
\text { zaron a cursar } \\
\text { las Licenciaturas. } \\
\text { Nos vamos para } \\
\text { arriba!!! Mejor } \\
\text { dicho, para la otra } \\
\text { cuadra... }\end{array}$ & $\begin{array}{l}\text { Si no hay tantos } \\
\text { libros como se } \\
\text { necesitan, enton- } \\
\text { ces los prestamos } \\
\text { menos tiempo a fin } \\
\text { de que todos pue- } \\
\text { dan "disfrutar" de } \\
\text { los mismos. Ahora } \\
\text { se presta TODO, o } \\
\text { casi todo, a domi- } \\
\text { cilio ya que no } \\
\text { damos abasto dado } \\
\text { el incremento de la } \\
\text { matrícula. Adapta- } \\
\text { mos la nueva casa } \\
\text { con la ayuda nues- } \\
\text { tros compañeros. } \\
\text { Pusimos estanterías } \\
\text { en el comedor, en } \\
\text { la cocina la heme- } \\
\text { roteca y en el living } \\
\text { la mapoteca. }\end{array}$ \\
\hline $\begin{array}{l}\text { La biblioteca se } \\
\text { muda, junto con } \\
\text { la Facultad de } \\
\text { Humanidades y } \\
\text { Ciencias a su nuevo } \\
\text { edificio de la Ciudad }\end{array}$ & $\begin{array}{l}\text { Otra mudanza, qué } \\
\text { desastre. Además } \\
\text { ahora es más lejos. }\end{array}$ & $\begin{array}{l}\text { Y si se nos pierden } \\
\text { libros, seguro que } \\
\text { nos hacen pagar } \\
\text { los "platos rotos" } \\
\text { a nosotros. }\end{array}$ & $\begin{array}{l}\text { El Pozo es otra } \\
\text { cosa, otra vida. Aquí } \\
\text { se respira el aire de } \\
\text { la Laguna Setúbal y } \\
\text { se aprecia un pai- } \\
\text { saje fenomenal. }\end{array}$ & $\begin{array}{l}\text { A partir del } 3 \text { de } \\
\text { Noviembre de } \\
2006 \text { se inauguró } \\
\text { la Biblioteca Cen- } \\
\text { tralizada FADU- } \\
\text { FHUC-ISM con la }\end{array}$ \\
\hline
\end{tabular}




\begin{tabular}{|c|c|c|c|c|}
\hline $\begin{array}{l}\text { Sombrero Blanco } \\
\text { pensamiento } \\
\text { neutro }\end{array}$ & $\begin{array}{l}\text { Sombrero Rojo } \\
\text { pensamiento } \\
\text { emocional }\end{array}$ & $\begin{array}{l}\text { Sombrero Negro } \\
\text { pensamiento } \\
\text { negativo }\end{array}$ & $\begin{array}{l}\text { Sombrero Amarillo } \\
\text { pensamiento } \\
\text { positivo }\end{array}$ & $\begin{array}{l}\text { Sombrero Verde } \\
\text { pensamiento } \\
\text { creativo }\end{array}$ \\
\hline $\begin{array}{l}\text { Universitaria en el } \\
\text { Paraje "El Pozo". }\end{array}$ & & & $\begin{array}{l}\text { Se suman propues- } \\
\text { tas educativas: más } \\
\text { licenciaturas, más } \\
\text { postgrados. La vida } \\
\text { de nuestros estu- } \\
\text { diantes se mezcla } \\
\text { con la de su pares } \\
\text { de facultades que ya } \\
\text { estaban en el lugar. } \\
\text { Además, en el año } \\
\text { 2006 la Biblioteca } \\
\text { "Alcira L. Plez" de la } \\
\text { Facultad de Humani- } \\
\text { dades y Ciencias se } \\
\text { transforma en Biblio- } \\
\text { teca Centralizada } \\
\text { FADU-FHUC-ISM. } \\
\text { Ahora atendemos } \\
\text { a más usuarios y } \\
\text { tenemos más como- } \\
\text { didades para todos. } \\
\text { También tenemos } \\
\text { cada vez mayor } \\
\text { cantidad de material } \\
\text { (30.000 volúmenes } \\
\text { aproximadamente). } \\
\text { Ya no solo ofrece- } \\
\text { mos libros, revistas, } \\
\text { CD-ROM, videos y } \\
\text { mapas sino también } \\
\text { casetes, partituras } \\
\text { y muchos más CDs. } \\
\text { Todo en beneficio de } \\
\text { nuestros usuarios. }\end{array}$ & $\begin{array}{l}\text { implementación } \\
\text { del acceso a } \\
\text { estante abierto } \\
\text { y de un sistema } \\
\text { automatizado para } \\
\text { el préstamo de } \\
\text { materiales que } \\
\text { beneficia a todos } \\
\text { los usuarios de } \\
\text { la comunidad } \\
\text { universitaria. } \\
\text { También, a partir } \\
\text { de esa fecha, se } \\
\text { comienza a aten- } \\
\text { der en horario } \\
\text { corrido. Un deseo } \\
\text { hecho realidad por } \\
\text { y para nuestros } \\
\text { usuarios. }\end{array}$ \\
\hline
\end{tabular}




\section{Sombrero Azul}

\section{Organiza el pensamiento, controla}

Hago lo que realmente me gusta, servir a los demás desde una biblioteca es una de las misiones en mi vida, de eso estoy segura. Tengo una buena relación con mis superiores y con las autoridades. Esto es, DEFINITIVAMENTE, lo mío. Encontré mi vocación casi sin querer.

Hay que entender a la biblioteca como una institución de servicio que debe ser administrada como tal. Gestionar información en el siglo XXI es todo un desafío. También hay que aprender a "operar" políticamente dado que estamos inmersos en un medio que así lo requiere y que la "buena cintura" y el "manejo inteligente" de las relaciones humanas es lo único que puede conducirnos al éxito, más allá de todas las reformas edilicias e infraestructurales que se realicen.

Haber crecido durante estos 17 años junto con al Facultad de Humanidades y Ciencias ha sido, y espero que siga siendo, un privilegio. Creo en la educación pública y gratuita de nuestros jóvenes como también creo en la capacidad de los trabajadores, docentes y no docentes, para construirla.

Referencias bibliográficas.

De Bono, Edward (2006): Seis sombreros para pensar.

Buenos Aires, Granica. 